\title{
CHINA'S MODEL OF FREE ECONOMIC ZONES: EXPERIENCES AND PROSPECTS AFTER OVER 20 YEARS
}

\author{
By Dr. Meng, Guangwen (China)
}

\begin{abstract}
:
It is true that no FEZs in the world like in China have made so strong impact on national economic development and reform. Their existing condition, however, has been changed since the middle 1990s. Chinese FEZs have to face the new challenges and problems. This study discussed and prospected the transformation and further development of Chinese FEZs in the $21^{s t}$ century as well as their significance for the transformation of FEZs in other country based on the analyzing of the indicators such as the role, policy, industrial sectors, administration, development model, spatial structure, and location in this study.
\end{abstract}

FEZ's Roles in Chinese Economic Development and Structural Reform

China's economic policy was transformed from the closed and inwardlyoriented development policies from 1949-1978 to an open and (coastal) outwardly-oriented economy since 1978. In order to develop a market economy and to reduce the risks of the reform, China's open policy and reform were first carried out in a small area in the 1980s. FEZs are used as experimental base and tool to carry out these reforms and to realize the economic development policy. In order to achieve high investment returns and attract foreign investment, the coastal region from the South to the North first enjoyed preferential policy and became the first growth axis of China in the 1980s. For promoting the economic development in the interior, three other growth axes were established in the 1990s, including Changjiang (Yangzi) Valley led by Shanghai; the Huanghe Valley (Yellow River) headed by Bohai Rim; and Border Regions touching northern, western and southern national borders. FEZs are set up as the growth poles of these four growth axes.

If the common features of Chinese FEZs are special economic policies and special objectives in a defined area, the essential distinction is their different industrial sector and locations. Chinese FEZs can be classified into "comprehensive, manufacture-based, science- and trade-based and crossborder FEZ", and numerous sub-typologies, including Special Economic Zones (SEZs), Technological and Economic Development Zones (TEDZs), 
Comprehensive Development Zones (CDZs), New and High Industrial Park (NHIPs), Free Trade Zones (FTZs), Free Frontier Trade Zones (FFTZs), Growth Triangle (GTs), Export Processing Zones (EPZs), and special administrative and economic zones (SAEZs). ${ }^{1}$

Following the regional opening, China's FEZs have been gradually established and have evolved in a special sequence since 1978. FEZs were first established in southern China in the early 1980s, have spread to northern China since the mid 1980s, and from the coastal region to the interior and border region since the 1990s. Most of them are also located in coastal region.

In general, FEZs in China are successful. A new generation and variation of FEZs was gradually created and they play a dominant role in China's rapid economic development and in the establishment of a market-oriented economy. It is true that no FEZs in the world, especially in developed countries, have had such strong impact on national economic development and transformation, which is new development of world FEZs.

\section{Micro Economic Achievements}

China's FEZs have achieved a great success since the 1980s. For example, GDP of five special economic zones (SEZs) with 35\% of average annual growth rate in 1997 reached 252 billion Yuan, and gross industrial output value (GIOV) reached 299 billion Yuan, an increase 100 times compared to 1980. GDP per capita in Shenzhen and Zhuhai SEZ were over US\$ 3000 in 1997, which ranked first and second place in the whole country at that time. Actually utilized foreign capital was US $\$ 33.4$ billion, making up about $15 \%$ of the whole country. ${ }^{2}$ GDP and total export of five SEZs and Pudong New Area (PNA) in 1999 reached 366.73 billion Yuan and US $\$ 36$ billion, and the latter made up over $20 \%$ of the nation. Especially, the average annual growth rate of Shenzhen SEZ from 1979 to 1999 reached $31.25 \%$, which occupied the first position of the large and midsize cities in China.

If economic and technological development zones (ETDZs), free trade zones (FTZs) and new and high industrial parks (NHIPs) are added, FEZs in China play an even more important role in national economy. For example, 32

\footnotetext{
${ }^{1}$ Meng Guangwen (2003), <<The Theory and Practice of Free Economic Zones, a Case Study of Tianjin / People's Republic of China >>, Peter Lang, Germany, pp. 81-86

${ }^{2}$ Ge Hongsheng (1998), "SEZ's Economy in the 21 Century", (21 Shiji De Teqiu Jingji), in: <<Yearbook of China's Special Economic Zone and Economic and Technological Development Zone 1998>>, Reform Publishing House, Beijing, pp. 1-2
} 
national ETDZs, accounting for almost one quarters of total 140 varied types of national FEZs, realized a rapid development. By 1998, their GIOV added up to 293.86 billion Yuan, a rise of $27.10 \%$ over 1997. The tax revenue reached 17.85 billion Yuan, an increase of $20 \%$ over 1997. Total export and total import reached US $\$ 10.65$ billion and US $\$ 8.13$ billion, which increased separately by $4.8 \%$ and $7.8 \%$ over 1997 . Their growth rates of major indicators were higher than the national average level. There were 12 enterprises whose GIOV exceeded 10 billion Yuan in $1998 .{ }^{3}$

By 1998, the 32 national ETDZs approved 13,454 foreign-funded enterprises over the years, which amounted to $4.10 \%$ of the whole country. Their contracted foreign capital and the foreign capital actually utilized reached US\$50.81 and 28.04 billion, which made up $8.90 \%$ and $10.50 \%$ of whole country's total value. The average foreign capital level and average foreign capital actually utilized were US\$3.77 and 2.08 million, which were much higher than the country's average level of US $\$ 1.76$ and 0.82 million. There were 1730 enterprises, whose investment exceeded US\$10 million. Among the global top 500 companies listed in Fortune magazine in 1998, 113 transnational companies invested in 32 national ETDZs. ${ }^{4}$

Following these economic developments, FEZs were transformed from attracting foreign and domestic capital to turning over taxation revenue, investing in the interior and promoting the economic development of economically backward regions. For example, Shenzhen SEZ realized 13.1 billion Yuan of local budgetary financial revenue in 1996, and 10.1 billion Yuan were turned over to the central government. Shenzhen SEZ aided the economic development of the western region with $2 \%$ of financial revenue, which it had budgeted. Most FEZs became the growth poles to develop the national economy and to recover the vitality of the traditional but outdated economic centers, such as PNA to Shanghai and TEDA to Tianjin.

\section{Macro Economic-Political Achievement}

Chinese FEZs are not only the windows of China's open policy, foreign capital, advanced technology and management experience, but also the

${ }^{3}$ Ai Chenglong, Ning Wei (1999), "The Current Situation and the Development of Economic and Technological Development Zones", In: $<<$ Study on Development Reference for Decision>>, 1999 Bound Volume, No. 178, TEDA, pp. 57-58

${ }^{4}$ Ai Chenglong, Ning Wei (1999), "The Current Situation and the Development of Economic and Technological Development Zones", In: $<<$ Study on Development Reference for Decision>>, 1999 Bound Volume, No. 178, TEDA, pp. 57-58 
experiment bases and the economic growth poles. FEZs, especially SEZs, provided useful experiences for China's structural reform. The general objective of China's structural reform is to establish a socialist market-oriented economy. The experiments were first carried out in SEZs and other FEZs, and then, the successful experiences were spread to the whole country. These successful experiences included the inviting-tenders system in the reform of basic construction, the transformation from two-price system to a market-oriented price system in the reform of the price system; the advertising and contract system in human resources management; the establishment of the stock market in the financial system; the reform of state-owned enterprises based on the stock system and the modern enterprise system; the legal transformation of state-owned land in the land use system; the social insurance system; the transformation of government function and ecology-oriented urban construction. ${ }^{5}$ Chinese FEZs presented the achievements of China's open policy and structural reform and promoted the implementation of China's regional development and the return to the motherland of Hong Kong and Macao.

\section{The Environment Changes of Chinese FEZs}

\section{Internal Environmental Change}

Based on the coast, FEZs have become either modern cities or urban economic centers. The regional disparity between the coast and inland and between FEZs and the other regions has been enlarged. If this model continues, the regional gap will be continually enlarged. That will go against China's own final objective, namely that the balanced development shall be realized by the unbalanced development, and will probably result in serious social and political problems.

As experimental bases for the market-oriented economy, FEZs enjoy preferential policy and privilege in order to achieve experiences for the whole country. But, along with the preliminary establishment of the socialist marketoriented economy, the remaining regions also demand preferential policy and privilege. In addition, due to time limits, the FEZ's preferential policy and privilege were either reduced or changed. The tax reduction and holiday, financial

${ }^{5}$ For discussion, see: Li Nanling, Chen Yani (2000), "The Great Project - SEZ's Historic Contribution to China's Open Policy and Reform), (Weida De Gongcheng Jingjiteqiu Dui Woguo Gaigekaifang De Lishi Gongxian), In: $<<$ People's Daily $>>$, Overseas Edition, 14-11-2000 
subsidy and administrative privilege were gradually replaced by reducing national customs duty, reduction of tax preference and financial subsidy as well as high-tech and industry-oriented preferential policy. Except export processing zones (EPZs), the duty free import of equipment, raw and semifinished material has been gradually canceled.

The establishment of FEZs in China and their development were unbalanced. The time difference of the establishment of various FEZs reached 14 years, and there were also 10-year time differences among the same type of FEZs. The different typologies and establishment times led to the different development levels of FEZs. For instance, the early established SEZs and ETDZs reached the growing stage and are beginning to be transformed to the flourishing stage. Their challenges are how to avoid economic recession and to realize the flourishing stage. Some other FEZs, however, such as FTZs, EHIPs and comprehensive development zones (CDZs), are in the transformation from the starting to the growing stage, and their challenge is how to realize economic growth. In addition, because of the different establishment time, FEZs in the same typology are also in different development stages. Some of the early established, national and provincial FEZs, possessing a favorable location and a rational development model, have become well-developed economic areas, modern cities or urban centers though some national FEZs, especially some provincial and local FEZs with unfavorable location conditions have faced a lot of problems, and are still in a dilemma.

\section{External Environment Change}

External environmental change means that treaty obligations and rights will influence FEZ preferential policy and privilege, as China became a full member of WTO in 2001. Besides the principles of most-favored-national treatment, national treatment, equality and mutual benefit, reduction of custom duty, WTO has also other principles of anti-dumping, anti-subsidy, anti-quota, transparency, unity of economic policy and low within national customs system. Some FEZ preferential policies and privileges, however, are in conflict with these principles, which will influence FEZ development in the future:

- Dumping and subsidy suspicion: based on export-oriented strategy, the varied kinds of preferential policies and privileges enjoyed by the investors within FEZs were combined with some quantity limits such as 
export quantity, balance of foreign exchange and domestic market quota. It is easy for this to result in dumping and subsidy suspicion.

- Non-unity and non-transparency: transparency and unity have a close linkage. Non-transparency means non-unity. FEZs carried out regionaloriented preferential policy and privilege. Because there are now so many types of Chinese FEZs and so many different preferential policies and privileges of FEZs that the non-unity and non-transparency will easily take place. For example, the same imported goods have different custom duties collected in different FEZs.

- FEZs were mostly located in the coastal region with well-development economy and advanced technology, there were fewer FEZs in inland, but the WTO encouraged the establishment of FEZs in underdeveloped regions.

\section{Transformation of China's FEZs: Models, Problems and Prospects}

\section{Transformation from a Window-Base-Bridge to a Growth Pole}

The model of "window-base-bridge" is a condensation of the FEZ's role in China's open policy and structural reform in the 1980s. This model stated that FEZs were the windows to present open policy and to absorb foreign capital, technology and management experience; an experimental base to carry out economic structural reform and establish a socialist market-oriented economy; and a bridge to linking national and international markets. Following economic development since the 1990s, FEZs have been transformed from more indirect economic and political roles to a more direct economic role in regional economic development. That is both the central governmental wish and the inner demand of FEZs itself. There are four models how FEZs promote the regional economic development. ${ }^{6}$

\section{Indirectly Promoting Role based on Model of "Window and Bridge"}

At the initial stage, the promoting role is regional economic cooperation. For example, the interior regions attracted foreign investment, expanded export and created employment by establishing "window-office" and "window-

${ }^{6}$ For discussion, see: Guo Zhemin (1997), "Giving full Play to Promotional Role of Special Economic Zone, Promoting Economic Development in Interior", (Fahui Teqiu De Daidong Zuoyun, Zujin Neidi Jingji Fazhan), In: $<<$ Theory and Practice of Special Economic Zone>>, (Teqiu Lilong Yu Shijian), No. 10, pp. 34-37 
enterprises", supplying labor services and participating in trade conversation in FEZs. Almost each province opened such "window-offices" in Shenzhen SEZ. Shenzhen SEZ offered inland employment to about two million in the 1980s. It is a successful model for regional economic cooperation.

\section{Aid to the Interior}

The undeveloped interior needs the financial support of the developed coastal region for its economic development. FEZs also have the responsibility to give help to the interior because they enjoyed first preferential policy and privilege, and their final objective is to realize common prosperous life in the whole country. Some FEZs have established "Funds of Economic Cooperation". There are three models of this aid: 1) counterpart regions based on the national arrangement, e.g. Shenzhen SEZ and Guizhou province, Xiamen SEZ, Ningxia, and Tibet autonomous region; 2) counterpart regions based on the provincial arrangement, e.g. Xiamen SEZ and Sanming and Longyan region; 3) special counterpart regions, namely, that FEZs and some government departments together give aid to certain special regions or units. This model, however, plays only a limited role because the funds are limited.

\section{Economic and Technological Cooperation}

The main cooperation form between SEZs and inland is that some military and state-owned large and mid-size enterprises established "Chinese-Chinese" and "Chinese-Foreign" joint ventures in order to utilize FEZ's preferential policy and market mechanism in the 1980s. And this model promoted not only FEZ's development, but also encouraged open policy and the economic development in inland. Following the increase of labor costs, some FEZ's labor-intensive industries moved inland, or FEZs established joint ventures with inland enterprises, or prophase and operate some inland enterprises. For example, enterprises in Shenzhen SEZ invested total 14 billion Yuan in the interior in 1995.

\section{Establishment of Economic Cooperation Area (ECA)}

It is a higher level of economic cooperation between FEZs and its adjacent regions to establish ECA, in which FEZs are regarded as the growth poles. With the support of the central government, the ECA of Yuedong-Gandongnan based on Shangtou SEZ, and the ECA of Minxinan based on Xiamen SEZ, were 
approved in 1995. However, the FEZ's success determined whether such ECAs were successful or not (see Fig. 1).

Fig. 1: The Models of FEZ's Promotion to the Regional Economic Development

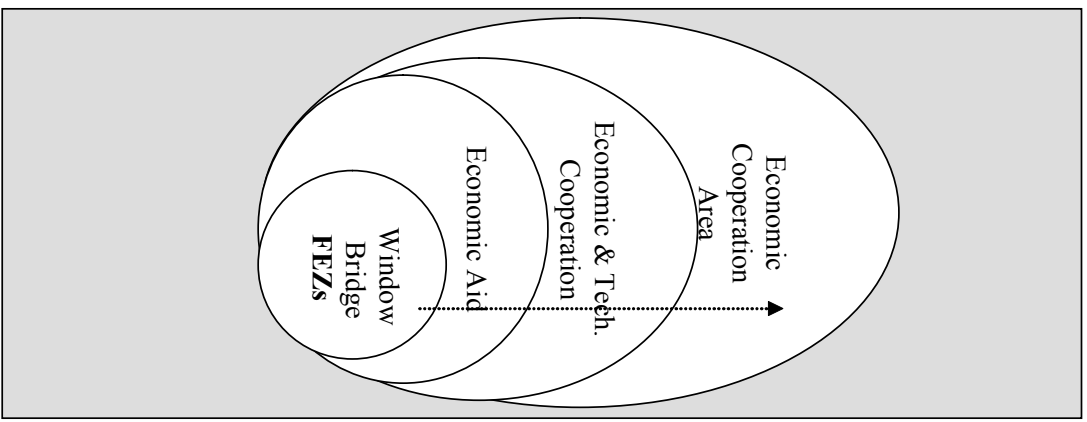

\section{Transformation of Regional-Oriented Preferential Policy}

Since 1996, FEZ's original preferential policy has been gradually reduced, but FEZ's advantages of capital, technology, qualified personnel and marketoriented economy have been strengthened. FEZ's development power has been transformed from the "preferential policy" to the "comprehensive economic and structural advantage". Secondly, in order to deepen reform, improve the socialist market-oriented economy and face the challenge of WTO and world regional economic integration (REI), FEZs should be continually used as the experimental base of REI, ${ }^{7}$ and provide the experience in the above-mentioned field for the whole country. Thirdly, the regional-oriented model made FEZs to be an outstanding "beneficiary". It led not only to the FEZ's rapid development, but also to the enlargement of the economic gaps between FEZs and the remaining regions and between the coast and the interior. This model also led to a lot of importation of industries with low technology and limited technological transfer.

In view of the above-mentioned facts, regional-oriented preferential policy should be transformed to the combination of regional-oriented and industryoriented preferential policy. The preferential policy will be transformed from FEZs to the remaining regions and from the coast to the interior, from all industrial

${ }^{7}$ Xinhua (2000), "Special Economic Zones should Pilot Path to Globalization", In: http:// www. chinatopnews. com, 2000-10-12 
sectors within the FEZs to some key industrial sectors within FEZs and in the rest regions. The strategy of the "great western development" in 2000 is an example. The new FEZs will be not established, but the industry-oriented preferential policy will enjoy by the western region. ${ }^{8}$ The preferential policy and privilege will be reduced gradually in a proper order from pillar industry to general industry and limited industry.

\section{The Combination of the Policy of Inside and Outside National Customs System}

Most trade-based and manufacture-based FEZs in the world carried out the "model of customs enclave" in order to realize their "pure economic objectives" by reducing and exempting from customs duty, but Chinese FEZs carried out the "model of inside national customs system" in order to realize their multi-economic and political objectives. Yet, this model has been challenged by the well-developed national market-oriented economy and the WTO's principles. According to international practice, the regions outside national customs system can carry out special economic policy that can be different from national economic policy. So, Chinese FEZs could carry out a new model in order to be not only in line with current Chinese law and policy to optimize the preferential policy and privilege, but also to show no difference with the WTO's general principles and international practices. This model should be the combination of the policy of both the inside and outside national customs system. In detail, some independent FTZs, EPZs and FFTZs carry out the policy of the customs system of enclave. FTZs, EPZs and free frontier free trade zones (FFTZs) within SEZs, ETDZs, CDZs and cross-border growth triangles (CGTs) also carry out this enclave policy, but NHIPs and the remaining regions of SEZs, ETDZs, CDZs and CGTs should enjoy only the policy of special customs supervision. Shenzhen SEZ, TEDA and Tianjin NHIP are three examples.

\section{Transformation of FEZ's Governance Structure}

The Chinese FEZ's governance structure was a horizontal combination of the integration and separation between FEZs and the administrative areas in the 1980s. That means that SEZ is the integrative model, but other typological FEZs are the separating model. Generally, the Chinese FEZ's governance

${ }^{8}$ Xinhua (2000), "No Special Economic Zone in Developing West China: Official", In: http://www.chinatopnews. com, 2000-10-20 
structure was transformed to the integrative model from the 1980s to the 1990s. As window, base, and bridge, the SEZ's integrative administrative model can successfully supply "general experiences" for the open policy and reform of the whole country. For example, Shenzhen SEZ separately established municipal government in the 1980s and the Municipal People's Congress in the early 1990s. At this stage, Shenzhen SEZ possessed an independent administrative system. In the lately 1990s, Shenzhen SEZ set up two districts of Nantou and Longgang by abolishing Baoan county. Shenzhen SEZ finally became a city subordinate to Guangdong province. Xiamen SEZ also is a city subordinated to Fujian province. Hainan SEZ is a complete provincial administrative system. Besides SEZs, some CDZs and some large ETDZs are developing towards the integration of FEZ and the administrative area. For example, Dalian municipality established "Jinwan New Area", in which Dalian ETDZ is regarded as the center and includes FTZ, Dayaowan port, Dalian NHIP and Jinshitan national tourist zone. The administrative committee of Jiwan New Area was established and developed into an integration of the FEZ and administrative area. ${ }^{9}$

But, due to the changes of FEZ's environment, the integration model is challenged: First, the increase of preferential policy and privilege will be contrary to the final objectives of Chinese reform and open policy and some WTO's principles. Second, if FEZs exist in name only, their accumulated economic resources will not be fully utilized. A possible way to avoid this is to transform the horizontal combination to the vertical combination of the integration and separation between FEZ and administrative area. For example, SEZs, CDZs and some large ETDZs should not only develop to a standard administrative area, but also maintain some FEZs such as ETDZ, FTZ, EPZ and NHIP. Shanghai PNA, Sozhou New Area (SNA) should become a combination of FEZ and an administrative area. ${ }^{10}$

\section{Transformation of Development Model}

The investment environment consists of preferential policy and welldeveloped infrastructure. The latter is the first step of the FEZ's establishment

${ }^{9}$ Chen Zhilong (1999), “The Developments of Development Zone in Our Country's Coastal Region and the Inspiration to the Development of Pudong New Area", (Woguo Yanhai Kaifaqiu Dongtai yiqi Dui Pudong Xinqiu Fazhan De Qishi), In: <<Shanghai Synthetical Economy>>, (Shanghai Zonghe Jingji), pp. 27-29

${ }^{10}$ Zhu Congshi, Weng Junyi (1997), "On the New Standardization of Special Economic Zone", (Long Jingji Teqiu De Chongxin Guifan), In: <<Economic Study $>>$, (Jingji Yianjiu), Beijing, pp. 61-65 
and development because most Chinese FEZs are located in the urban periphery or in a remote area. Based on a suitable distance to urban center, these areas have only a low developed infrastructure. The land development, including leveling land (earth fill), road, drainage, water supply, electric power, cogeneration of power and heat, communications, fuel gas and greenery, is just to supply the international standard infrastructure for the investors. For achieving capital and funds, Chinese FEZs have experienced three models: small-scale circulatory land development, large-scale circulatory land development and industrial development, and finally capital operation.

\section{Small-Scale Circulatory Land Development}

FEZs use credit, governmental financial allocation or foreign capital to develop land and infrastructure, and then, the developed land will be sold or leased to the foreign or domestic enterprises at attractive price. The land charge and taxation will be used again for further land development. A continuing circle will finally be established. At this stage, many foreign enterprises will invest in FEZs. Land development begins to be transformed into industrial development. Nearly all of Chinese FEZs used this model to create infrastructure, especially at their initial stages.

Fig. 2: The Model of Small-Scale Circulatory Land Development of Chinese FEZs

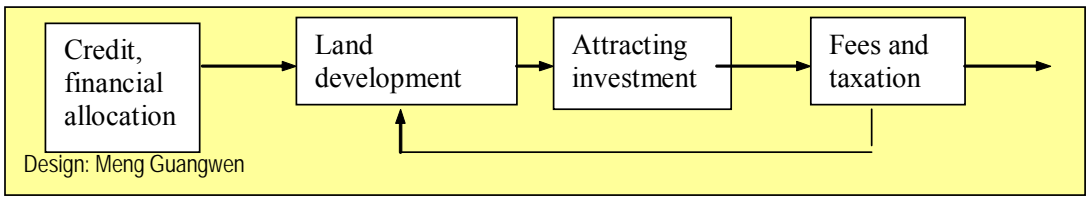

\section{Large-Scale Circulatory Land and Industrial Development}

FEZs transfer the right to foreign or domestic contractors to develop a large stretch of land area. There are two possibilities. First, the foreign or domestic contractors construct the infrastructure of a large stretch of land area, attract or invite the investors, pay the rent and taxes, and FEZs use them to develop the rest of the zone. Second, foreign or domestic contractors will be entrusted by FEZs with full responsibility for the whole zone's infrastructure and industrial development. This model was used to the FEZs with the large area or they are at higher development stage, for example, Yangpu development 
zone in Hainan SEZ, Taiwanese investment zone in Xiamen SEZ, SNA and in some large ETDZs such as TEDA. At this stage, numerous foreign enterprises will invest in FEZs. Tax revenue and service income are more than the land charge. This means that the motive power of FEZs has been transformed from land development to industrial development.

\section{Fig. 3: The Model of Large-Scale Land and Industrial}

Development of Chinese FEZs

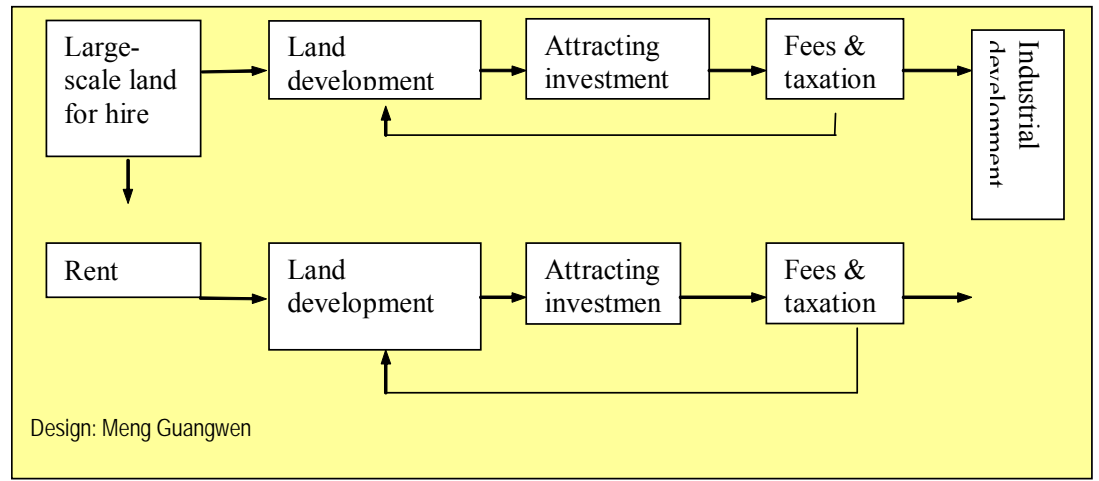

The Capital Operation as the New Trends of Development Model

There were two new trends of Chinese FEZ's land development in the 1990s. First, Chinese FEZs carried out new large-scale infrastructure construction, especially, the large transport and communication projects in the 1990s in order to optimize the investment environment, urban function, and to absorb transnational companies. The airport and seaport in Shenzhen SEZ and in PNA are examples. Second, the capital operation includes land development in other regions and the establishment of its own enterprises. FEZs use own well-known brands and surplus funds to establish sub-zones in other regions or in foreign countries, as they do not have enough space, but have accumulated abundant funds. FEZs can also use their funds accumulated by land and industrial development to invest in industrial sectors in order to increase the capital in value. For example, TEDA purchase enterprises and shares/stocks or established their own stock companies. 


\section{Transformation from an Outwardly-Oriented}

\section{Economy to an Open Economy}

The outwardly-oriented economy based on the labor-intensive industry was the one of the FEZ's key objectives from the 1980s to the 1990s and it has already been established or is being established in the most Chinese FEZs. Since the lately 1990s, FEZ's development strategy has been transformed to an open economy, and has paid more attention to the domestic market. That means that FEZs should use part of the domestic market to exchange foreign advanced technology of transnational companies. Transnational companies have a worldwide market system and advanced technology. They invested in FEZs not only for the cheap labor force, but also for the new market. The exchange of market and technology should meet the needs of both sides so that the FEZ policy of promoting export and limiting the sales inside domestic market has been weakened since the lately 1990s. Hereafter, the transnational companies have become the FEZ's key investors and motive power. Based on the industrial linkage and market strategy of transformational company, FEZs established gradually a closer economic linkage with national economy, and the domestic market has become their second development driving force. Motorola's large investment in TEDA, and IBM's investment in Shenzhen SEZ are just two examples. Several successful FEZs have moved from exporting commodities to exporting capital.

\section{Transformation from Labor-Intensive to Technology-Intensive Industry}

Most FEZs were established in the areas with extensive agriculture or backward industry, while today they have established their own industrial structure characterized by the labor-intensive pillar industries. Since the late 1990s, the FEZ industrial structure has been transformed. The capital-intensive, high-tech, and the tertiary industries have increased. For example, Shenzhen SEZ has encouraged the high-tech industry since 1995, and its output made up over $35 \%$ of total GDP in 1998 .

The Chinese FEZs have transformed from the growth in quantity in the 1980s has been transformed into the growth in quality in the late 1990s. The upgrading of industrial structure is the driving force of this transformation so that FEZs paid more attention to develop their own new and high-tech industries or to absorb high-tech industry based on original industrial base. The preferential policy has been oriented to the new and high-tech industries. 


\section{Transformation from Intra-National to Cross-border and Cross-National Regional Cooperation}

Most FEZs had planned a small area at their starting stages, but some of them were already fully developed in the 1990s. The successful FEZs used their well-known brand, capital, and personnel advantage to expand their areas and established sub-zones in domestic and foreign countries so that the FEZ's spatial structure has been changed from the small zone to the large zone and from the single zone to the multi-zones. For example, Shenzhen SEZ not only expanded its area to the whole Baoan County, but also established $37 \mathrm{~km}^{2}$ of "Longgang Industrial Development Zone" and "Wutongshan Tourism Zone" in its eastern part. Dalian and TEDA also expanded their areas and transformed from the single zone to the multi-zones. In 2002, Kunming NHIP in Yunnan province and Thailand government planned to establish a FTZ in northern Thailand.

FEZs became the regional growth poles to promote regional development. The horizontal economic cooperation inside FEZs and between FEZs and the remaining regions promoted the establishment of several intra-national Growth Triangles (GTs), such as the regional GT of Bohai Bay headed by Beijing, Tianjin and Dalian, the regional GT of Changjiang Delta headed by Shanghai and the central regional GT headed by Wuhan and Chungqing as well as GT of Zhujiang Delta-Hong Kong-Macao-Taiwan. In addition to accelerating national and regional development and acting as "experimental hot houses" and foreign exchange generators, the FEZs continued to promote the "United Front" goals of integrating the mainland with Hong Kong/Macao and Taiwan. As early as 1981, the Central Committee stated that the SEZs would "reassure the Hong Kong and Macao peoples and achieve the return of Taiwan to the Motherland". Guangdong, and Shenzhen SEZ authorities as well as private Hong Kong entrepreneurs have: a) financed railroad, electrification and the construction of superhighways linking Hong Kong/Macao with the SEZs and the interior; b) simplified border crossing procedures; c) increased cross-border policy coordination. Since the return of Hong Kong to China in 1997 and Macao in 1999, the cooperation and coordination in economic development and urban construction between the Mainland and Hong Kong and Macao have been strengthened. The railway from Beijing to Hong Kong was opened to traffic in 2000. In 2002, a free trade area (FTA) between the mainland, Hong Kong and Macao was planned. Although there are grave divergences of unification between the Mainland and Taiwan, the "Three Openings", namely, the opening 
of navigation, air traffic, and postal route, are being discussed REI would be the first step and the basis of the unification of the Mainland and Taiwan. FEZs would play a dominant role in this process. ${ }^{11}$

Since the Taiwanese government first allowed military veterans to visit the mainland relatives in 1987, over 5 million Taiwanese have visited the mainland, and invested over US\$20 billion in the coastal economy until the 1990s, including US\$2.4 billion in the Xiamen SEZ. To accommodate Taiwanese investors in Fujian Province, the State Council already approved the establishment of "Taiwanese Investment Zones" (TIZs) in May 1989. Located in the Xiamen SEZ and the Fuzhou Mawei ETDZ, these zones offered Taiwanese special privileges to establish "foreign-invested enterprises". TIZs have been also established inside other ETDAs or in other coastal open cities since the 1990s. Since the late 1990s, Shanghai has become the new center of Taiwanese investment.

Following rapid economic development, China will become a new regional economic center in the $21^{\text {st }}$ century and will make notable impact on the world and Asian economic development. In addition, world REI and the WTO will promote China to use FEZs and other well-developed economic centers with favorable locations to carry out cross-border and cross-national economic cooperation. China will play a leading role in this economic cooperation and integration, and will establish its own regional markets. The economic relative underdeveloped neighboring countries might have misgivings, but the prospective economic benefit will encourage their economic and technological cooperation with China. Intra-national economic cooperation, cross-border and cross-nation economic and political cooperation will be the development trend of the Chinese FEZs in the $21^{\text {st }}$ century. Besides CGTs of Tumen River and Mekong-Lancang River, the possible cross-border and cross-national economic and political GTs should be China-Mongolia and China-Central Asian, FTA of China-ASEAN, China-Korea-Japan (see Fig. 4).

${ }^{11}$ Lawrence C. Reardon (1996), "The Rise and Decline of China's Export Processing Zones”, In: <<Journal of Contemporary China $>>$, No. 5(13) 


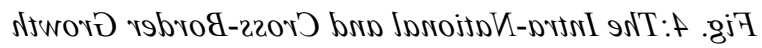

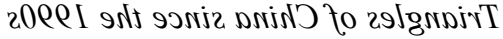

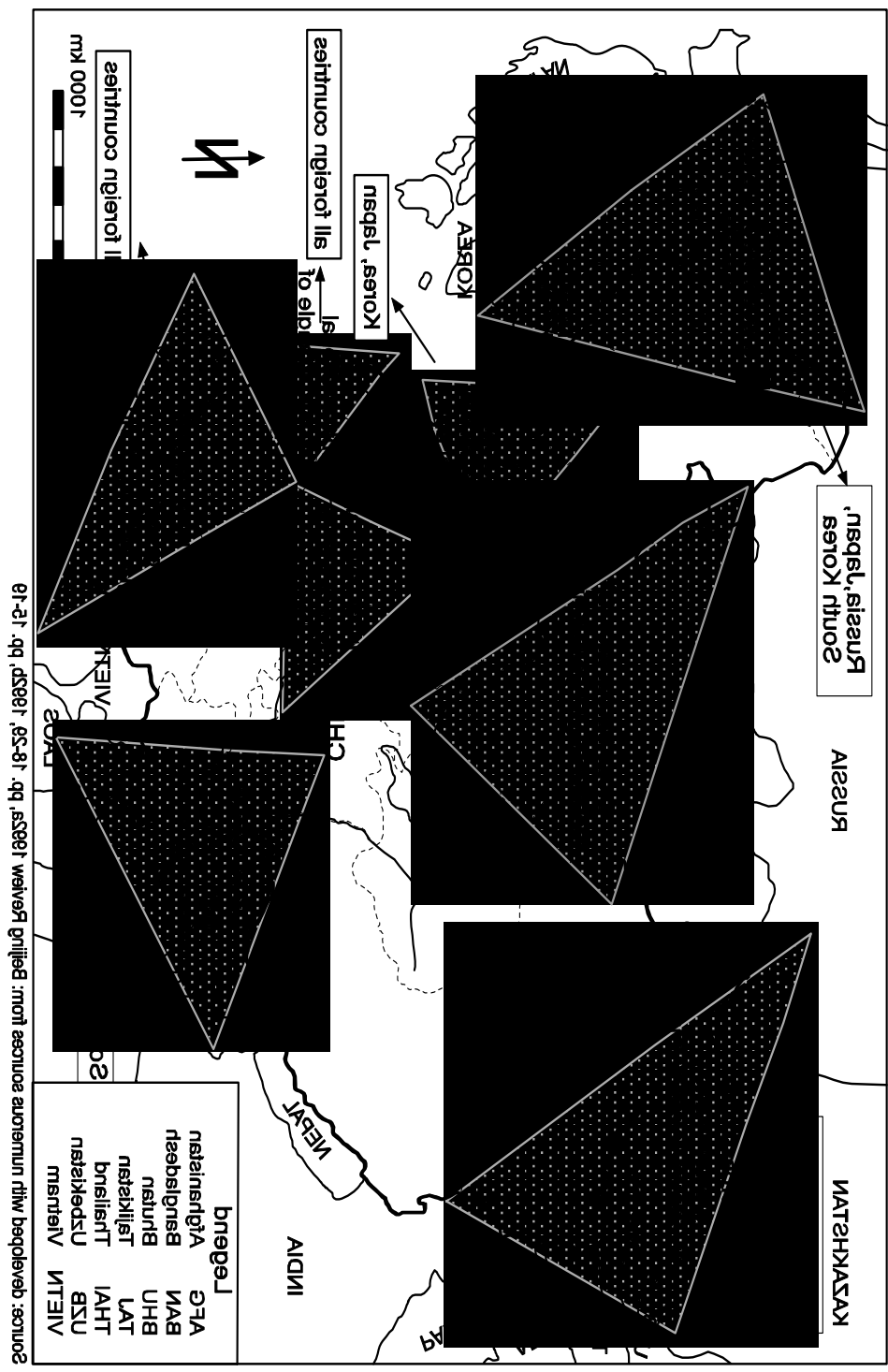




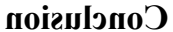

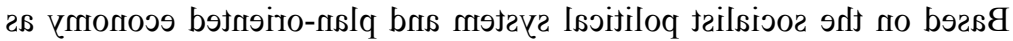

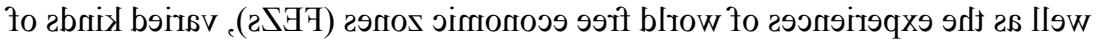

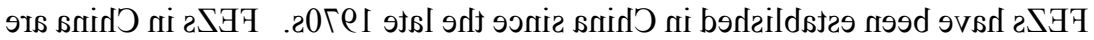
үIlsubsig гsw гS

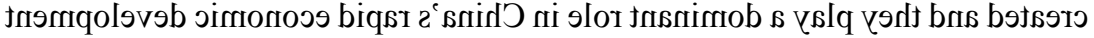

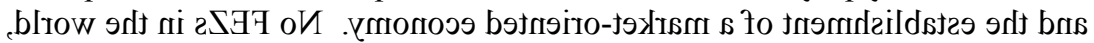

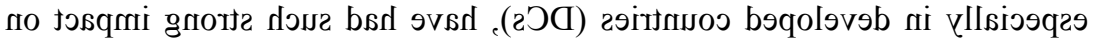

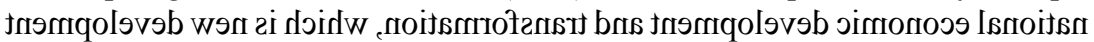

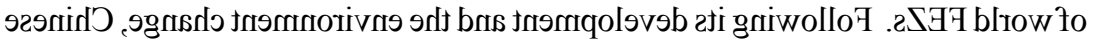

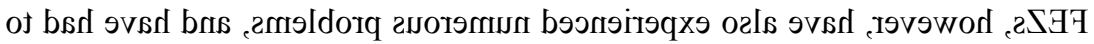

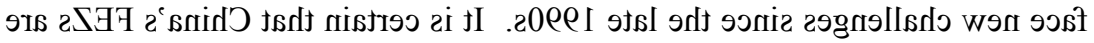

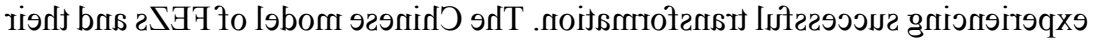

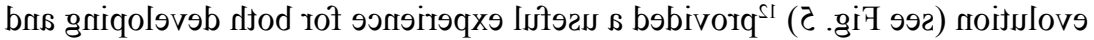

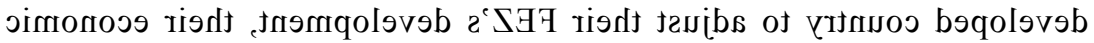

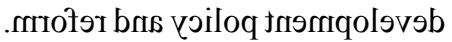

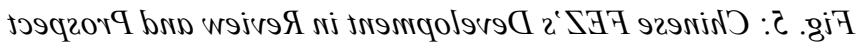

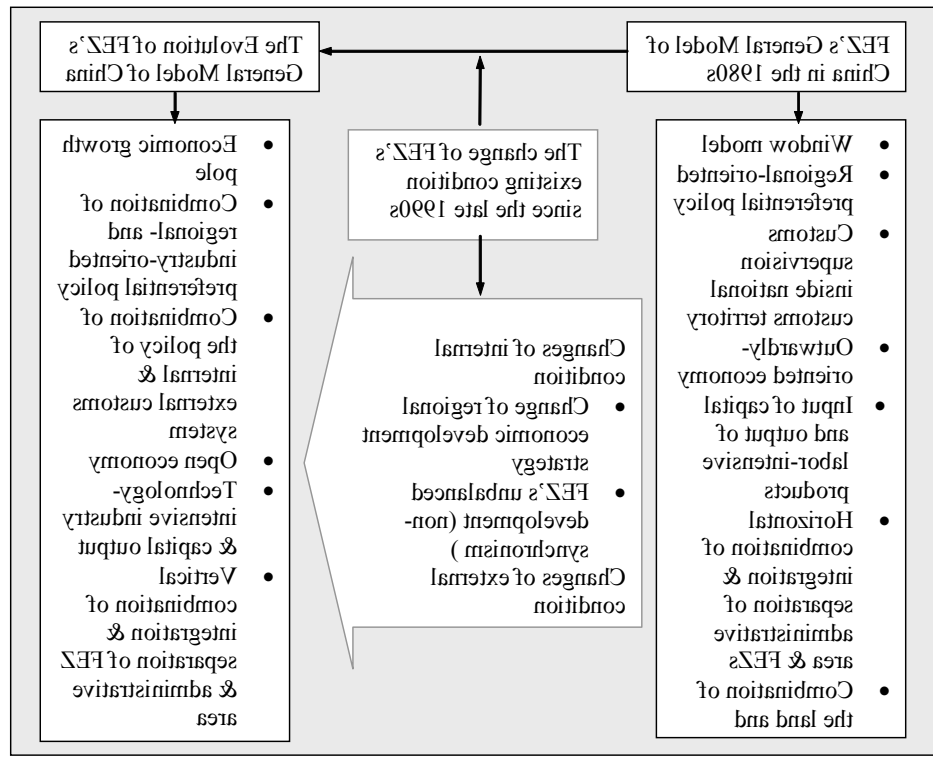

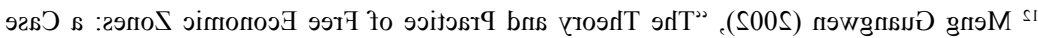

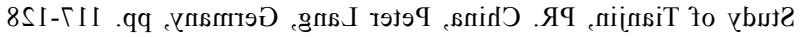




\section{List of References}

Ai Chenglong, Ning Wei (1999), "The Current Situation and the Development of Economic and Technological Development Zones", In: $<<$ Study on Development - Reference for Decision>>, 1999 Bound Volume, No. 178, TEDA, pp. 57-58

Chen Zhilong (1999), “The Developments of Development Zone in Our Country's Coastal Region and the Inspiration to the Development of Pudong New Area", (Woguo Yanhai Kaifaqiu Dongtai yiqi Dui Pudong Xinqiu Fazhan De Qishi), In: <<Shanghai Synthetical Economy $>>$, (Shanghai Zonghe Jingji), pp. 27-29

Ge Hongsheng (1998), "SEZ's Economy in the 21 Century", (21 Shiji De Teqiu Jingji), in: $<<$ Yearbook of China's Special Economic Zone and Economic and Technological Development Zone 1998>>, Reform Publishing House, Beijing, pp. 1-2

Guo Zhemin (1997), "Giving full Play to Promotional Role of Special Economic Zone, Promoting Economic Development in Interior", (Fahui Teqiu De Daidong Zuoyun, Zujin Neidi Jingji Fazhan), In: $<<$ Theory and Practice of Special Economic Zone>>, (Teqiu Lilong Yu Shijian), No. 10, pp. 34-37

Lawrence C. Reardon (1996), "The Rise and Decline of China's Export Processing Zones”, In: <<Journal of Contemporary China $>>$, No. 5(13)

Li Nanling, Chen Yani (2000), "The Great Project - SEZ's Historic Contribution to China's Open Policy and Reform), (Weida De Gongcheng Jingjiteqiu Dui Woguo Gaigekaifang De Lishi Gongxian), In: $<<$ People’s Daily $>>$, Overseas Edition, 14-11-2000

Meng Guangwen (2002), "The Theory and Practice of Free Economic Zones: a Case Study of Tianjin, PR. China, Peter Lang, Germany

Xinhua (2000), "Special Economic Zones should Pilot Path to Globalization", In: http:// www. chinatopnews. com, 2000-10-12

Xinhua (2000), "No Special Economic Zone in Developing West China: Official”, In: http://www.chinatopnews. com, 2000-10-20

Zhu Congshi, Weng Junyi (1997), "On the New Standardization of Special Economic Zone”, (Long Jingji Teqiu De Chongxin Guifan), In: $<<$ Economic Study $>>$, (Jingji Yianjiu), Beijing, pp. 61-65 